\title{
Short-Term Effects of Structured Education on Breastfeeding
}

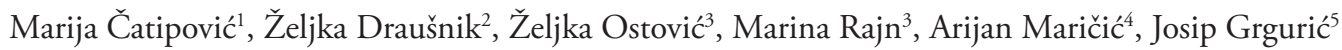 \\ ${ }^{1}$ Specialist Pediatric Office, Bjelovar, Croatia; ${ }^{2}$ Department for Public Health, Croatian Institute of Public Health, Zagreb, \\ Croatia, ${ }^{3}$ Medical School Bjelovar, Bjelovar, Croatia, ${ }^{4}$ XVI. Gynasium Zagreb, Zagreb, Croatia, ${ }^{5}$ United Nations International \\ Children's Emergency Fund, Office for Croatia, Zagreb, Croatia
}

Correspondence: zeljka.drausnik@hzjz.hr; Tel.: + 38514863 244; Fax.: + 38514683011

Received: June 2, 2021; Accepted: September 12, 2021

\begin{abstract}
Objective - Since it is known that awareness and attitudes about breastfeeding are formed in adolescence, the goal of this study was to question the short-term effects of structured breastfeeding education on a sample of students from a medical high school in Croatia. Materials and Methods - Students from Medical School in Bjelovar were participants of this study; the experimental group consisted of 89 fourth graders versus 52 first graders in the control group. Their intentions, attitudes and knowledge about the breastfeeding were measured using a Breastfeeding Intentions, Attitudes and Knowledge questionnaire before the four-hour structured educational course was held, then 3 weeks and 3 months after the education. The results of the experimental group, who participated in the course, and the control group, who did not participate in the course, were compared. Results - In the control group there were no significant differences in the results of the questionnaire of the participants between the first and the later two surveys. The results of the experimental group differ notably in all aspects of the questionnaire and the overall results of the questionnaire when comparing the results prior to the course and those 3 weeks and 3 months after it. The outcome of the course was better in women. The results of the knowledge questionnaire showed an inconsistent correlation with the results of the intentions and attitudes questionnaires. Conclusion - The results confirm, the statistically significant improvement of attitudes, intentions and knowledge about breastfeeding in the experimental group, after the educational course on breastfeeding. Education about breastfeeding should contain not only recent information about breastfeeding but also specific activities aimed at correcting students' attitudes and intentions regarding breastfeeding.
\end{abstract}

Key Words: Students • Breastfeeding • Knowledge • Attitudes • Education.

\section{Introduction}

Although breastfeeding provides numerous health benefits for both mothers and infants, worldwide breastfeeding rates are lower than the United $\mathrm{Na}$ tions International Children's Emergency Fund (UNICEF) and World Health Organisation (WHO) recommend (1). To raise awareness and positive attitudes regarding breastfeeding, the best way is early education, starting from school age (2). There is scientific incoherence about the efficiency of educational interventions later in life and it seems certain that attitudes regarding breastfeeding are formed in adolescence and it is difficult to change already formed attitudes (3-5). Therefore, it seems logical to intervene before negative attitudes are formed.

Worldwide, the current state of high school education on the topic of breastfeeding is not clearly structured in its content or in its implementation and breastfeeding education is not considered mandatory, even for health workers $(6,7)$. In Croatia, breastfeeding education is part of the curriculum of the interdisciplinary subject Health for third and 
fourth grades of 4-year and second and third grades of 3-year high schools (8), but with no elaboration of the programme.

The aims of this study were to analyze the efficiency of structured breastfeeding education for students from the Bjelovar Medical School, to analyze the effect of gender and school achievements on the outcome of the education, and to point out the correlation of the results on scales of attitudes, intentions and knowledge together with the overall results of the questionnaire.

\section{Methods}

\section{Study Design and Participants}

This was a quantitative, longitudinal, quasi-experimental study, with the intervention being a structured educational course about breastfeeding.

The study was conducted at Bjelovar Medical School in Bjelovar, Croatia. The participants were first and fourth grade students, divided into experimental and control groups. The experimental group consisted of 89 fourth graders versus 52 first graders in the control group. The control group consisted of first graders in order to demonstrate the ineffectiveness of their three-year unstructured breastfeeding education, with the expectation of no statistically significant differences in the results of first and fourth graders from the first test (before conducting the structured breastfeeding course). No extra control group was formed consisting of only fourth graders, not participating in the structured breastfeeding education, because there were not enough fourth graders (the school has only two fourth-grade classes). In the experimental group there were 21 excellent students (20 girls and 1 boy); in the control group there were 15 excellent students (14 girls and 1 boy). Inclusion criteria included being a first or fourth grader of Bjelovar Medical School, not having their own children, the ability to use a computer, and giving informed written consent.

The questionnaire used for the purposes of this study was the Breastfeeding Intentions, Attitudes and Knowledge Questionnaire (BIAKQ) (9). The questionnaire consists of 3 scales - intentions, attitudes and knowledge. The scale intentions includes the participant's projection of intentions regarding breastfeeding in the future as a parent, and the questions differ in form for men and women. Questions regarding intentions for men are formatted as ways of supporting the mother. Questions on the attitudes scale are the same for both women and men. Answers on the intentions and attitudes scales are given in the form of agreeing/disagreeing and are graded using a 5-point Likert scale. The possible answers were: completely disagree, somewhat disagree, neither disagree not agree, somewhat agree and completely agree. The knowledge scale examines acquired knowledge on the topic of breastfeeding, and the questions do not differ for men and women. Possible answers given on the knowledge scale were 'Correct' and 'Incorrect'. In the scoring of the BIAKQ, instructions given in the questionnaire were used. Of the sociodemographic data, only the participants' gender and school success were taken into consideration.

The study was conducted in three phases, the first being completing the BIAKQ in both the experimental and control groups. After that, the experimental group had a 4-hour structured educational course on breastfeeding, which took place over the course of two days and was given by teachers from the Medical School. The first part, entitled 'Breastfeeding Saves Lives', was created to try to interest students in the topic of breastfeeding. During the second part, 'The Importance of Breastfeeding in a Child's Diet', students participated in and listened to an interactive presentation to understand the topic better, including a quiz on the topic. The third part, 'Attitudes towards Breastfeeding' involved a discussion between students and coming to conclusions. The fourth part, 'My Life Choices', dealt with the relationship between intentions, efforts and habits and included writing 'A letter of support to a friend who breastfeeds'. Three weeks and three months after the education participants took the survey again..

From the experimental group 84 students participated in the first survey, 81 in the second and 
79 in the third; from the control group 36 participated in the first and 32 and 27 in the second and third surveys, respectively. For the final evaluation the results were included of 22 participants from the control group (20 female and 2 male students) and 76 participants from the experimental group (62 female and 14 male students), who correctly filled out the questionnaires in all three parts of the testing.

The study was conducted from 1 February 2019 to 31 May 2019. The BIAKQ was posted on the website of the civil society association "For a Healthy and Happy Childhood" and students participated in the survey anonymously using school computers. They did not receive any reward for participating in the study. Written and informed consent for participation was obtained from each participant. For participants who were minors consent was given by the parents, as well as the participants themselves.

\section{Ethics Statement}

The study was approved by the Croatian Ministry of Science and Education and by the Ethics Committee of Bjelovar Medical School on December 20. 2019, under the registration number 2103-65-01-19-2.

\section{Statistical Analysis}

Participants' results on the intentions, attitudes and knowledge scales as well as the overall score from the BIAKQ questionnaire (continuous variable) were used as the dependent variable. The independent variable was the participants' assigned group (experimental/control), sex and school success (categorical variables. "School success was evaluated according to the final grade from the previous school year. Although there were only 14 male participants, this was a sufficient number of participants for the Wilcoxon Signed-Rank Test. The normality of the distribution of the differences in the results before and after the course, as well as the differences between the results of the two groups was examined using skewness and kurtosis, histogram, box plot, the Q-Q plot and the Kolomogorov-Smirnov and the Shapiro-Wilk tests. The presence of deviating elements was examined using a boxplot. The results pointed to the asymmetrical distribution of results, with plenty of deviation in the experimental group (certain individuals' results deviated greatly from the majority). The significance of the result shift between the different surveys (the first in comparison to the second and third) for the experimental and the control groups, and for the male and female participants in the experimental group was analysed using the Wilcoxon signed-rank test. The significance of the differences between the results of the experimental and control groups, as well as between students with excellent school success and others, was examined using the Mann-Whitney U test. The correlation between school success (excellent/not excellent) and the results on the scales and the overall questionnaire results for the experimental group, as well as the correlation of results on individual scales of the questionnaire with one another and together with the overall results, were shown using the Spearman correlation coefficient. The testing was two-way, with the coefficient of significance of $\mathrm{P}<0.05$.

\section{Results}

The results of the participants from the control group show no significant difference between the first and the other two surveys $(\mathrm{P}=0.05)$. The results of the participants in the experimental group differ significantly on all scales and overall results when comparing the first and second as well as the first and third rounds. There was virtually no difference in the results between the second and third rounds, which indicates the importance of the duration of the effect after the education. When comparing the results of the participants from the control and experimental groups, there was no difference in the first round (before the structured educational course), but the difference is significant when comparing the results in the second and third rounds (after the structured course) (Table 1). 
Table 1. The Difference in Results between the First round and Three Weeks and Three Months Later for Both the Participants in the Experimental and Control Groups as Well as the Difference in Results between the Control and Experimental Groups $(\mathrm{N}=98)$

\begin{tabular}{|c|c|c|c|c|c|c|c|c|}
\hline \multirow{2}{*}{ Variable } & \multirow{2}{*}{$\begin{array}{l}\text { Comparison } \\
\text { of Surveys }\end{array}$} & \multicolumn{2}{|c|}{ Control group $(\mathrm{N}=22)$} & \multicolumn{2}{|c|}{ Experimental group $(\mathrm{N}=76)$} & \multirow{2}{*}{ Surveys } & \multicolumn{2}{|c|}{ Control/ experimental group } \\
\hline & & $Z_{\text {value }}{ }^{*}$ & $P$ value & $Z$ value ${ }^{*}$ & $\mathrm{P}$ value & & $\mathrm{U}_{\text {value }}^{\dagger}$ & $P$ value \\
\hline \multirow{3}{*}{ Intentions } & $1^{\text {st }}: 2^{\text {nd }}$ & $-0.225^{\ddagger}$ & 0.82 & $-5.730^{\ddagger}$ & $0.00^{\S}$ & $1^{\mathrm{st}}$ & 801,00 & 0.77 \\
\hline & $1^{\mathrm{st}}: 3^{\text {rd }}$ & $-0.264 \|$ & 0.79 & $-5.021^{\ddagger}$ & $0.00^{\S}$ & $2^{\text {nd }}$ & 547.00 & $0.01^{\S}$ \\
\hline & $2^{\text {nd }}: 3^{\text {rd }}$ & $-0.683^{\|}$ & 0.49 & $-1.185^{\|}$ & 0.24 & $3^{\text {rd }}$ & 583.50 & $0.03^{\S}$ \\
\hline \multirow{3}{*}{ Attitudes } & $1^{\text {st }}: 2^{\text {nd }}$ & $-1.966 \|$ & 0.05 & $-7.194^{\ddagger}$ & $0.00^{\S}$ & $1^{\mathrm{st}}$ & 660.00 & 0.13 \\
\hline & $1^{\text {st }}: 3^{\text {rd }}$ & $-1.265^{\|}$ & 0.21 & $-6.981^{\ddagger}$ & $0.00^{\S}$ & $2^{\text {nd }}$ & 625.00 & $0.07^{\S}$ \\
\hline & $2^{\text {nd }}: 3^{\text {rd }}$ & $-0.519^{\ddagger}$ & 0.60 & $-0.267^{\ddagger}$ & 0.79 & $3^{\text {rd }}$ & 609.50 & 0.05 \\
\hline \multirow{3}{*}{ Knowledge } & $1^{\text {st }}: 2^{\text {nd }}$ & $-1.275^{\|}$ & 0.20 & $-2.941^{\ddagger}$ & $0.00^{\S}$ & $1^{\mathrm{st}}$ & 717.50 & 0.29 \\
\hline & $1^{\mathrm{st}}: 3^{\text {rd }}$ & $-0.528^{\ddagger}$ & 0.60 & $-3.487^{\ddagger}$ & $0.00^{\S}$ & $2^{\text {nd }}$ & 591.50 & $0.02^{\Im}$ \\
\hline & $2^{\text {nd }}: 3^{\text {rd }}$ & $-1.799 \|$ & 0.07 & $-0.709^{\ddagger}$ & 0.48 & $3^{\text {rd }}$ & 377.00 & $0.00^{\S}$ \\
\hline \multirow{3}{*}{ Overall } & $1^{\text {st }}: 2^{\text {nd }}$ & $-0.553^{\|}$ & 0.58 & $-7.107^{\ddagger}$ & $0.00^{\S}$ & $1^{\mathrm{st}}$ & 699.50 & 0.25 \\
\hline & $1^{\mathrm{st}}: 3^{\mathrm{rd}}$ & $-1.466 \|$ & 0.14 & $-6.991^{\ddagger}$ & $0.00^{\S}$ & $2^{\text {nd }}$ & 584.00 & $0.03^{\S}$ \\
\hline & $2^{\text {nd }}: 3^{\text {rd }}$ & $-0.970^{\|}$ & 0.33 & $-0.313^{\|}$ & 0.75 & $3^{\text {rd }}$ & 577.00 & $0.03^{5}$ \\
\hline
\end{tabular}

"Wilcoxon Signed Ranks Test; ${ }^{\dagger}$ Mann-Whitney U Test; ${ }^{\ddagger}$ Based on positive ranks; ${ }^{\circledR} \mathrm{P}<0.05$; "Based on negative ranks.

Table 2. Differences between the Results of the First, Second and Third Surveys for Male and Female Participants in the Experimental Group $(\mathrm{N}=76)$

\begin{tabular}{|c|c|c|c|c|c|}
\hline \multirow{2}{*}{ Variable } & \multirow{2}{*}{ Comparison of Surveys } & \multicolumn{2}{|c|}{ Women $(\mathrm{N}=62)$} & \multicolumn{2}{|c|}{ Men $(\mathrm{N}=14)$} \\
\hline & & $\mathrm{Z}^{*}$ & $P$ value & $\mathrm{Z}^{*}$ & $P$ value \\
\hline \multirow{3}{*}{ Intentions } & $1^{\text {st }}: 2^{\text {nd }}$ & $-5.765^{\dagger}$ & $0.00^{\ddagger}$ & $-1.258^{\dagger}$ & 0.21 \\
\hline & $1^{\text {st }}: 3^{\text {rd }}$ & $-4.976^{\dagger}$ & $0.00^{\ddagger}$ & $-1.290^{\dagger}$ & 0.20 \\
\hline & $2^{\text {nd }}: 3^{\text {rd }}$ & $-1.303^{\S}$ & 0.19 & $-0.206^{\dagger}$ & 0.84 \\
\hline \multirow{3}{*}{ Attitudes } & $1^{\text {st }}: 2^{\text {nd }}$ & $-6.571^{\dagger}$ & $0.00^{\ddagger}$ & $-2.973^{\dagger}$ & $0.00^{\ddagger}$ \\
\hline & $1^{\text {st }}: 3^{\text {rd }}$ & $-6.436^{\dagger}$ & $0.00^{\ddagger}$ & $-2.692^{\dagger}$ & $0.01^{\ddagger}$ \\
\hline & $2^{\text {nd }}: 3^{\text {rd }}$ & $-0.464^{\dagger}$ & 0.64 & $-0.849^{\S}$ & 0.40 \\
\hline \multirow{3}{*}{ Knowledge } & $1^{\text {st }}: 2^{\text {nd }}$ & $-3.334^{\dagger}$ & $0.00^{\ddagger}$ & $-0.705^{\dagger}$ & 0.48 \\
\hline & $1^{\text {st }}: 3^{\text {rd }}$ & $-3.119^{\dagger}$ & $0.00^{\ddagger}$ & $-1.628^{\dagger}$ & 0.10 \\
\hline & $2^{\text {nd }}: 3^{\text {rd }}$ & $-0.156^{\dagger}$ & 0.88 & $-1.063^{\dagger}$ & 0.29 \\
\hline \multirow{3}{*}{ Overall } & $1^{\text {st }}: 2^{\text {nd }}$ & $-6.473^{\dagger}$ & $0.00^{\ddagger}$ & $-2.982^{\dagger}$ & $0.00^{\ddagger}$ \\
\hline & $1^{\text {st }}: 3^{\text {rd }}$ & $-6.466^{\dagger}$ & $0.00^{\ddagger}$ & $-2.587^{\dagger}$ & $0.01^{\ddagger}$ \\
\hline & $2^{\text {nd }}: 3^{\text {rd }}$ & $-0.205^{\S}$ & 0.84 & $-0.551^{\S}$ & 0.58 \\
\hline
\end{tabular}

'Wilcoxon Signed Ranks Test; ${ }^{\dagger}$ Based on positive ranks; ${ }^{\ddagger} \mathrm{P}<0.05$; ${ }^{\circledR}$ Based on negative ranks. 
Table 3. The Difference in Results of the Participants of the Experimental Group according to School Success (excellent/non-excellent) $(\mathrm{N}=52)$

\begin{tabular}{llll}
\hline \multirow{3}{*}{ Variables } & $\begin{array}{l}\text { Comparison } \\
\text { of Surveys }\end{array}$ & \multicolumn{2}{c}{ Excellent/non-excellent } \\
\cline { 3 - 4 } Intentions & $1^{\text {st }}$ & 444.00 & 0.12 \\
\cline { 2 - 4 } & $2^{\text {nd }}$ & 442.00 & 0.11 \\
\cline { 2 - 4 } & $3^{\text {rd }}$ & 441.00 & 0.11 \\
\hline \multirow{3}{*}{ Attitudes } & $1^{\text {st }}$ & 364.00 & $0.01^{\dagger}$ \\
\cline { 2 - 4 } & $2^{\text {nd }}$ & 529.50 & 0.58 \\
\cline { 2 - 4 } Knowledge & $3^{\text {rd }}$ & 444.50 & 0.12 \\
\hline & $1^{\text {st }}$ & 555.00 & 0.78 \\
\hline & $2^{\text {nd }}$ & 520.00 & 0.44 \\
\hline \multirow{3}{*}{ Overall } & $3^{\text {rd }}$ & 501.50 & 0.29 \\
\cline { 2 - 4 } & $1^{\text {st }}$ & 375.50 & $0.02^{\dagger}$ \\
\cline { 2 - 4 } $2^{\text {nd }}$ & 512.00 & 0.45 \\
\cline { 2 - 4 } & $3^{\text {rd }}$ & 430.50 & 0.09 \\
\hline
\end{tabular}

*Mann-Whitney U Test; ${ }^{\dagger} \mathrm{P}<0.05$.

Women scored a statistically much higher difference in their results on all scales and the overall results of the questionnaire in the first and the second rounds, as well as between the first and the third rounds. Men only scored a significant difference between the first and the second, and the second and third surveys on the attitudes scale and the overall results (but not on the intentions and knowledge scales) (Table 2).

The results of the participants differ according to school success only in the first survey. The first round of the survey was conducted before the structured educational course on breastfeeding was held, and significant differences between excellent and other students in terms of attitudes and the overall results of the questionnaire were confirmed. However, in the second and third rounds, after the structured educational course on breastfeeding was held, the differences between excellent and other students were lost, which indicates that the effec-
Table 4. Correlation between School Success and the

Participants' Results before the Course, and 3 Weeks and 3 Months Later $(\mathrm{N}=52)$

\begin{tabular}{|c|c|c|c|}
\hline \multirow[b]{2}{*}{ Variables } & \multirow{2}{*}{$\begin{array}{l}\text { Comparison of } \\
\text { Survey Results }\end{array}$} & \multicolumn{2}{|l|}{ Excellent school success } \\
\hline & & $\begin{array}{l}\text { Spearman Correlation } \\
\text { Coefficient }\end{array}$ & $P$ value \\
\hline \multirow{3}{*}{ Intentions } & $1^{\text {st }}$ & 0.18 & 0.12 \\
\hline & $2^{\text {nd }}$ & 0.18 & 0.12 \\
\hline & $3^{\text {rd }}$ & 0.18 & 0.11 \\
\hline \multirow{3}{*}{ Attitudes } & $1^{\text {st }}$ & 0.29 & $0.01^{\dagger}$ \\
\hline & $2^{\text {nd }}$ & 0.06 & 0.58 \\
\hline & $3^{\text {rd }}$ & 0.18 & 0.12 \\
\hline \multirow{3}{*}{ Knowledge } & $1^{\text {st }}$ & 0.03 & 0.78 \\
\hline & $2^{\text {nd }}$ & -0.09 & 0.45 \\
\hline & $3^{\text {rd }}$ & 0.12 & 0.29 \\
\hline \multirow{3}{*}{ Overall } & $1^{\text {st }}$ & 0.27 & $0.02^{\dagger}$ \\
\hline & $2^{\text {nd }}$ & 0.09 & 0.45 \\
\hline & $3^{\text {rd }}$ & 0.20 & 0.09 \\
\hline
\end{tabular}

${ }^{\star}$ Excellent success $=1$; Non-excellent $=0 ;{ }^{\dagger} \mathrm{P}<0.05$.

tiveness of the educational program was the same for all students, regardless of their previous school success (Table 3).

School success only had a significant statistical correlation with the participants' results in the first survey, and only with the results of the attitudes scale and the overall results. After the course was conducted, the difference between the results decreased (Table 4).

The results of the intentions and attitudes scales had a high level of correlation, just as they have a high level of correlation with the overall results of the questionnaire. The results of the knowledge scale show an unstable correlation, while there was no correlation from the knowledge and intentions scales in the first and third surveys, with the knowledge and attitudes scales in the second and third surveys, or with the knowledge scale and the overall results of the third testing (Table 5). 
Table 5. The Correlations between the Results of the Participants of the Experimental Group from the Intentions, Attitudes and Knowledge Scales as well as the Overall Results on the BIAKQ ( $N=52)$

\begin{tabular}{|c|c|c|c|c|c|}
\hline Variables & & & Attitudes & Knowledge & Overall \\
\hline \multirow{6}{*}{$1^{\text {st }}$ survey } & \multirow{2}{*}{ Intentions } & Spearman's correlation & 0.68 & 0.14 & 0.79 \\
\hline & & $P$ value & $0.00^{*}$ & 0.22 & $0.00^{*}$ \\
\hline & \multirow{2}{*}{ Attitudes } & Spearman's correlation & - & 0.34 & 0.98 \\
\hline & & P value & - & $0.00^{*}$ & $0.00^{*}$ \\
\hline & \multirow{2}{*}{ Knowledge } & Spearman's correlation & - & - & 0.36 \\
\hline & & $P$ value & - & - & $0.00^{*}$ \\
\hline \multirow{6}{*}{$2^{\text {nd }}$ survey } & \multirow{2}{*}{ Intentions } & Spearman's correlation & 0.74 & 0.28 & 0.85 \\
\hline & & $P$ value & & $0.01^{*}$ & $0.00^{*}$ \\
\hline & \multirow{2}{*}{ Attitudes } & Spearman's correlation & - & 0.19 & 0.98 \\
\hline & & P value & - & 0.10 & $0.00^{*}$ \\
\hline & \multirow{2}{*}{ Knowledge } & Spearman's correlation & - & - & 0.25 \\
\hline & & $P$ value & - & - & $0.03^{*}$ \\
\hline \multirow{6}{*}{$3^{\text {rd }}$ survey } & \multirow{2}{*}{ Intentions } & Spearman's correlation & $0.00^{*}$ & 0.14 & 0.86 \\
\hline & & P value & - & 0.24 & $0.00^{*}$ \\
\hline & \multirow{2}{*}{ Attitudes } & Spearman's correlation & - & 0.17 & 0.97 \\
\hline & & P value & - & 0.15 & $0.00^{*}$ \\
\hline & \multirow{2}{*}{ Knowledge } & Spearman's correlation & - & - & 0.19 \\
\hline & & $P$ value & - & - & 0.10 \\
\hline
\end{tabular}

Spearman's correlation=Spearman rank-order correlation coefficient; ${ }^{*} \mathrm{P}<0.05$.

\section{Discussion}

The short-term positive effects of breastfeeding education on students' attitudes, intentions and knowledge have been confirmed by studies by other authors. However, it must be taken into account that the positive effects of education begin to fade after 6 months, so a new cycle of re-education is essential (10-12). The knowledge of future nurses regarding breastfeeding is insufficient, and correctly conceived education programmes could resolve this and improve their knowledge and attitudes $(13,14)$.

In this study, the results of the experimental group differ greatly on all the scales, as well as the overall results of the questionnaire when comparing the results before the educational course and the results three weeks and three months after it, which confirms the efficiency of the course. The lack of significant differences between the results of the second and the third surveys confirms that the course was effective for at least three months. In the control group there were no such positive shifts in intentions, attitudes, knowledge and overall results from the breastfeeding questionnaire between the first, second and third round - the students of the control group did not achieve any statistically significant positive shifts. It is important to emphasise that in the first round there were no statistically significant differences either on the intentions, attitudes, knowledge scales or in the overall results, when comparing the results of students of the control and experimental groups. This means that, regardless of their previous education on breastfeeding, the students in the experimental group did not have better results than the students in the control group. Since students of the medical school attend breastfeeding education as part of the subject "Healthcare of a Healthy Child and Adolescent" in the third grade (so neither the experimental nor the control group students at the time of the study had 
been exposed to the effects of breastfeeding education in their regular classes), we can assume that the differences identified in the participants' results are the result of the structured education on breastfeeding conducted as part of this research.

This study showed that the education had a greater impact on female than on male participants. The female respondents from the experimental group achieved positive results on all scales and the overall results in both the second and third rounds (compared to the results of first round). However, the success of male respondents is not negligible. They achieved a significant positive difference in the second and third rounds on the attitudes scale and the overall results. The slight and inconsistent effects of breastfeeding education on the knowledge and intentions of male participants have also been confirmed by other studies (15). One possible explanation is that the medical education system is burdened by gender roles (16), which in turn creates an academic environment that is less stimulating for boys than for girls. However, other studies show an overall lower concern for breastfeeding in men, which can be linked to the fact that they are not biologically determined to breastfeed, that is the physiological component which makes breastfeeding seem real and immediate (17). The support of a partner is very important when it comes to breastfeeding, so not only for professional but also for personal reasons young men should be motivated and presented with the topic of breastfeeding in a way that is interesting to them and will help them realize the importance of their role in it, as early as possible in their education (18-20).

Considering that the students of the experimental group had taken the school subject "Healthcare of a Healthy child and Adolescent" in the previous school year, part of which was breastfeeding education, we expected that students who had completed the previous grade with excellent results would have slightly better results from the breastfeeding questionnaire compared to other students, and this study confirmed this. However, the aim of this study was to determine whether the course conducted was effective for all students, regardless of their previous school success. Good quality education should bring about changes in intentions, attitudes and knowledge in all students, not only excellent students who already show positive results. The results show that after the course the difference was not as prevalent, which means that the course was equally as effective for all participants, no matter how well they were doing in school. That is a good result because it means that the course is applicable to all participants. The same conclusion was confirmed by the next analysis, which showed that the final grade in the previous school year (the third grade, in which students in the experimental group had formal education on breastfeeding as part of the school subject "Healthcare of Healthy Children and Adolescents") correlates statistically significantly with the results of respondents on the knowledge scale and the overall results of the questionnaire, but only in the first round, before the structured breastfeeding course.

The correlation between the individual scales of the questionnaire together with the overall results of the questionnaire is not the same for all the scales. The results of the intentions and attitudes scales correlate strongly with the overall results from all three surveys, while for knowledge we did not find any significant correlation with the overall results in the third survey. Attitudes only correlate significantly with knowledge in the first survey, intentions with knowledge only in the second survey, while intentions and attitudes significantly correlate with one another in all three surveys. This points to a limited impact that knowledge has on intentions and attitudes towards breastfeeding, as well as shorter effect that education has on knowledge about breastfeeding when compared to intentions and attitudes. A high level of knowledge about breastfeeding is not often followed by the same level of positive intentions and attitudes towards breastfeeding, which can be explained by the lack of a clinical component in breastfeeding education for future health workers $(21,22)$.

There is an abundance of educational programmes on breastfeeding on offer, but a lack of structured analyses that would differentiate the 
quality of programmes in a sense of their measurable efficiency (14). This problem will not be solved until more schools in a certain geographic and cultural area who offer structured educational programmes on breastfeeding start participating in multicentre research using the same measuring instrument (23). The only institutions which possess the authority necessary to encourage authors from different institutions and fields of study to participate in a project under the same methodological conditions are large professional and international organizations which deal with the promotion of breastfeeding and advocate for the introduction of breastfeeding education $(2,24)$, and it is unlikely that such research will be carried out without their help.

The low response rate of first grade students and the inconsistency in their attendance shows that they are uninterested and unmotivated for this topic, partly due to the assumption that they have not yet developed the awareness medical workers need to have, and the commitment to help and support others. Considering the fact that parental consent was necessary for the participation of underage students, parents' negative attitudes towards the goals of the research could have impacted student's response rates.

Unstructured breastfeeding education, the way it is currently being taught in Croatian schools, cannot produce satisfactory results. The education is not conducted according to a single, structured programme, but it is up to individual teachers to determine how they will teach the topic, which means that students in different classes and schools receive different information, which has not been reviewed. This study goes to show that clear, structured and professionally reviewed breastfeeding education can be offered to students. Although the topic of breastfeeding should be the part of the curriculum for the interdisciplinary topic 'Health' in medical high schools in Croatia, the curriculum needs be uniform at a national level, and local authorities could consider the possibility of providing additional education for teaching staff.

In this research, the effects are shown of theoretical breastfeeding education on the attitudes, knowledge and intentions of students. The search is in progress for the competent authority to approve research into the effects of education of future health workers which includes practical education on breastfeeding. The programme includes (together with the theoretical activities presented here) visits to maternity hospitals, attending childbirth, participating in the work of breastfeeding support groups, participating in the work of pregnancy courses, helping to arrange events such as "The Beauty of Motherhood" and "The Beauty of Family", participation in an education programme entitled "Pharmacies - Friends of Breastfeeding" and marking the National and International Breastfeeding Weeks.

The next phase of this study should be the acquisition of approval to conduct and validate the efficiency of the programme, including the practical part of the course. The educational programme will be proposed to a competent ministry in the form of workshops for teachers, so their preparedness to conduct the curriculum may be improved.

\section{Limitations of the Study}

Despite the fact that there were no differences between the experimental and control groups before the structured course, since they are not in the same grade it is possible that students were exposed to the other, different information in the school curriculum and other influences in their lives, which could influence the results.

\section{Conclussion}

This study confirms the possible positive influence of this programme of theoretical education for medical school students on breastfeeding, and indicates the need for further studies on this issue. Since we are aware of the importance of practical work with parents and children when it comes to breastfeeding support, the effects and efficiency of education, with and without practical work, should be the topic of future studies. 
Authors' Contributions: Conception and design: MĆ and JG; Acquisition, analysis and interpretation of data: MĆ, ŽO, MR; Drafting the article: MĆ, ŽD, ŽO, MR, AM and JG; Revising the article critically for intellectual content: MĆ, ŽD, $\check{Z} \mathrm{O}, \mathrm{MR}, \mathrm{AM}$ and JG; Approved final version of the manuscript: MĆ, ŽD, ŽO, MR, AM and JG.

Conflict of Interest: The authors declare that they have no conflict of interest.

\section{References}

1. The World Bank Data. [cited 2021 May 15]. Available at: https://data.worldbank.org/indicator/SH.STA.BFED.ZS? end $=2008 \&$ locations $=$ HR\&start $=2005$.

2. Singletary N, Chetwynd E, Goodell LS, Fogleman A. Stakeholder views of breastfeeding education in schools: a systematic mixed studies review of the literature. Int Breastfeed J. 2017;12:14. doi: 10.1186/s13006-0170106-0. PMID: 28360927; PMCID: PMC5368914.

3. Lumbiganon P, Martis R, Laopaiboon M, Festin MR, Ho JJ, Hakimi M. Antenatal breastfeeding education for increasing breastfeeding duration. Cochrane Database Syst Rev. 2011;(11):CD006425. doi: 10.1002/14651858. CD006425.pub2. Update in: Cochrane Database Syst Rev. 2012;9:CD006425. PMID: 22071830; PMCID: PMC4164447.

4. Yurtsal ZB and Kocoglu G. The effects of antenatal parental breastfeeding education and counseling on the duration of breastfeeding, and maternal and paternal attachment. Integr Food Nutr Metab. 2015;2:222-30. doi: 10.15761/IFNM.1000134

5. Goulet C, Lampron A, Marcil I, Ross L. Attitudes and subjective norms of male and female adolescents toward breastfeeding. J Hum Lact. 2003 Nov;19(4):402-10. doi: 10.1177/0890334403258337. PMID: 14620454.

6. Chuisano SA, Anderson OS. Assessing Application-Based Breastfeeding Education for Physicians and Nurses: A Scoping Review. J Hum Lact. 2020;36(4):699-709. doi: 10.1177/0890334419848414. Epub 2019 May 21. PMID: 31112052.

7. Folker-Maglaya C, Pylman ME, Couch KA, Spatz DL, Marzalik PR. Implementing a Breastfeeding Toolkit for Nursing Education. J Perinat Neonatal Nurs. 2018;32(2):15363. doi: 10.1097/JPN.0000000000000330. PMID: 29689016.

8. Decision on adoption of the curriculum for the cross-curricular topic Health for primary and secondary schools in the Republic of Croatia. Official Gazette of the Republic of Croatia, 10/19.
9. Čatipović M, Marković M, Grgurić J. Development and Validation of a Questionnaire on Breastfeeding Intentions, Attitudes and Knowledge of a Sample of Croatian Secondary-School Students. Children (Basel). 2018;5(5):56. doi: 10.3390/children5050056. PMID: 29702616; PMCID: PMC5977038.

10. Ho YJ, McGrath JM. Effectiveness of a Breastfeeding Intervention on Knowledge and Attitudes Among High School Students in Taiwan. J Obstet Gynecol Neonatal Nurs. 2016;45(1):71-7. doi: 10.1016/j.jogn.2015.10.009. Epub 2015 Dec 1. PMID: 26815800.

11. Reyes C, Barakat-Haddad C, Barber W, Abbass-Dick J. Investigating the effectiveness of school-based breastfeeding education on breastfeeding knowledge, attitudes and intentions of adolescent females. Midwifery. 2019;70:6470. doi: 10.1016/j.midw.2018.12.010. Epub 2018 Dec 14. PMID: 30580074.

12. Čatipović M, Markovic M, Grgurić J. Educational intervention about breastfeeding among secondary school students. Health Educ. J. 2018;118(3):339-53. doi:10.1108/ HE-10-2017-0057.

13. Bozzette M, Posner T. Increasing student nurses' knowledge of breastfeeding in baccalaureate education. Nurse Educ Pract. 2013;13(3):228-33. doi: 10.1016/j. nepr.2012.08.013. Epub 2012 Oct 2. PMID: 23040006.

14. Yang SF, Salamonson Y, Burns E, Schmied V. Breastfeeding knowledge and attitudes of health professional students: a systematic review. Int Breastfeed J. 2018;13:8. doi: 10.1186/s13006-018-0153-1. PMID: 29483935; PMCID: PMC5819656.

15. Martens PJ. The effect of breastfeeding education on adolescent beliefs and attitudes: a randomized school intervention in the Canadian Ojibwa community of Sagkeeng. J Hum Lact. 2001;17(3):245-55. doi: 10.1177/089033440101700308. PMID: 11847990.

16. O'Lynn CE. Gender-based barriers for male students in nursing education programs: prevalence and perceived importance. J Nurs Educ. 2004;43(5):229-36. doi: 10.3928/01484834-20040501-08. PMID: 15152800.

17. Čatipović M, Novalić D, Kanis Uldrijan K, Grgurić J. Parenting support in Bjelovar-Bilogora County. Paediatr Croat. 2019;63(Suppl 2):49-56.

18. Mannion CA, Hobbs AJ, McDonald SW, Tough SC. Maternal perceptions of partner support during breastfeeding. Int Breastfeed J. 2013;8(1):4. doi: 10.1186/1746-4358-84. PMID: 23651688; PMCID: PMC3653816.

19. Tohotoa J, Maycock B, Hauck YL, Howat P, Burns S, Binns CW. Dads make a difference: an exploratory study of paternal support for breastfeeding in Perth, Western 
Australia. Int Breastfeed J. 2009;4:15. doi: 10.1186/17464358-4-15. PMID: 19943958; PMCID: PMC2788531.

20. Juliff D, Downie J, Rapley P. Knowledge and attitudes of secondary school students to breastfeeding. Neonatal, Paediatr. Child Health Nurs. 2007;10(3):13-8.

21. Ben Natan M, Haikin T, Wiesel R. Breastfeeding knowledge, attitudes, intentions, and perception of support from educational institutions among nursing students and students from other faculties: A descriptive cross-sectional study. Nurse Educ Today. 2018;68:66-70. doi: 10.1016/j. nedt.2018.05.026. Epub 2018 Jun 1. PMID: 29886287.
22. Spear HJ. Baccalaureate nursing students' breastfeeding knowledge: A descriptive survey. Nurse Educ Today. 2006;26(4):332-7. doi:10.1016/j.nedt.2005.10.014.

23. Glaser DB, Roberts KJ, Grosskopf NA, Basch CH. An Evaluation of the Effectiveness of School-Based Breastfeeding Education. J Hum Lact. 2016;32(1):46-52. doi: 10.1177/0890334415595040. Epub 2015 Jul 14. PMID: 26173810.

24. Feldman-Winter L, Barone L, Milcarek B, Hunter K, Meek J, Morton J et al. Residency curriculum improves breastfeeding care. Pediatrics. 2010;126(2):289-97. doi: 10.1542/peds.2009-3250. Epub 2010 Jul 5. PMID: 20603262. 